\title{
Neural cell-surface and intracellular autoantibodies in patients with cognitive impairment from a memory clinic cohort
}

\author{
Niels Hansen ${ }^{1} \cdot$ Berend Malchow $^{1} \cdot$ Inga Zerr $^{2,3} \cdot$ Winfried Stöcker $^{5} \cdot$ Jens Wiltfang ${ }^{1,3,4} \cdot$ Charles Timäus $^{1}$
}

Received: 11 October 2020 / Accepted: 8 February 2021 / Published online: 6 March 2021

(c) The Author(s) 2021

\begin{abstract}
Autoantibody-associated cognitive impairment is an expanding field in geriatric psychiatry. We aim to assess the association between the presence of specific neural autoantibodies and cognitive performance in a memory clinic cohort. 154 patients with cognitive impairment were included between 2019 and 2020 presenting initially in a memory clinic. We evaluated their patient files retrospectively applying epidemiologic parameters, psychopathology, neuropsychology, intracellular and membrane-surface autoantibodies in serum and cerebrospinal fluid (CSF) and markers of neurodegeneration in CSF. In 26 of 154 patients, we searched for neural autoantibodies due to indicators for autoimmunity. In 15/26 (58\%) of patients we detected serum and/or CSF autoantibodies. We identified autoantibodies against intracellular or cell-surface antigens in 7 of all 26 (27\%) patients with cognitive dysfunction, although we cannot exclude patients with potential specific autoantibodies lacking autoimmune indicators. There were no significant differences between psychopathological and neuropsychological profiles in groups of patients with cognitive impairment comprising patients with autoantibodies (ABS + COG), no autoantibodies (ABS - COG), and Alzheimer's disease (ADCOG). Concerning our CSF parameters, we detected intrathecal IgG synthesis in $14 \%$ of ABS + COG and in $13 \%$ of ABS - COG patients, whereas no intrathecal IgG synthesis was found in ADCOG patients. Furthermore, CSF A 342 was significantly diminished in the ADCOG compared to the ABS + COG group $(p<0.05)$. In addition, the Aß42/40 ratio was lower in ADCOG patients than in the ABS + COG or ABS - COG group $(p<0.05)$. Our findings reveal the underestimated occurrence and autoantibodies' potential role in patients presenting cognitive impairment. Furthermore, the patients with possible Alzheimer's disease might be differentiated from autoantibodypositive patients via a reduced $A ß 42$ and $A \beta 42 / 40$ ratio in the CSF. The antibody-type varies between patients to a relevant degree, thus demonstrating the need for more research to identify subgroup-specific phenotypes. These pilot study results open an avenue for improving diagnosis and treatment in a memory clinic.
\end{abstract}

Keywords Autoimmunity $\cdot$ Cognitive impairment $\cdot$ Neural autoantibodies

Niels Hansen

niels.hansen@med.uni-goettingen.de

1 Department of Psychiatry and Psychotherapy, University Medical Center of Göttingen, University of Goettingen, Von-Siebold-Str. 5, 37075 Goettingen, Germany

2 Department of Neurology, University of Goettingen, Robert-Koch Str. 40, 37075 Goettingen, Germany

3 German Center for Neurodegenerative Diseases (DZNE), Von-Siebold-Str. 3a, 37075 Goettingen, Germany

4 Neurosciences and Signaling Group, Institute of Biomedicine (iBiMED), Department of Medical Sciences, University of Aveiro, Aveiro, Portugal

5 Euroimmun Reference Laboratory, Seekamp 31, 23650 Luebeck, Germany
Abbreviations

ABS + COG Autoantibodies and cognitive impairment $\mathrm{ABS}-\mathrm{COG}$

No autoantibodies and cognitive impairment

AD Alzheimer's disease

ADCOG Alzheimer's disease with cognitive impairment

AMPAR $\quad \alpha$-Amino-3-hydroxy-5-methyl-4isoxazolepropionic acid receptor

ARHGAP26 Rho GTPase-activating protein 26

Aß40

Aß42

CASPR2

Beta Amyloid 40

Beta Amyloid 42

CERAD

CSF
Consortiussociated protein tike 2

um to establish a registry for

Alzheimer's disease

Cerebrospinal fluid 


$\begin{array}{ll}\text { DPPX } & \text { Dipeptidyl-peptidase-like protein } 6 \\ \text { FTD } & \text { Frontotemporal dementia } \\ \text { GAD65 } & \text { Glutamic acid decarboxylase 65 } \\ \text { GDS } & \text { Geriatric depression scale } \\ \text { GluA3 } & \text { Subunit ionotropic glutamate receptor 3 } \\ \text { IgA } & \text { Immunoglobulin A } \\ \text { IgG } & \text { Immunoglobulin G } \\ \text { IgM } & \text { Immunoglobulin M } \\ \text { ITPR1 } & \text { Inositol 1,4,5-triphosphate receptor 1 } \\ \text { KCNA2 } & \text { Potassium voltage-gated channel subfam- } \\ & \text { ily A member 2 } \\ \text { LBD } & \text { Lewy Body dementia } \\ \text { MCI } & \text { Mild cognitive impairment } \\ \text { MMSE } & \text { Mini Mental Status Examination } \\ \text { MOG } & \text { Myelin oligodendrocyte glycoprotein } \\ & \text { (MOG) } \\ \text { MRI } & \text { Magnetic resonance imaging } \\ \text { N } & \text { Number } \\ \text { NMDAR } & N \text {-Methyl-D-aspartate receptor } \\ \text { OCB } & \text { Oligoclonal bands } \\ \text { PDD } & \text { Parkinson's disease dementia } \\ \text { Pre-GLRA1 } & \text { Pre glycine receptor alpha 1 } \\ \text { pTau181 } & \text { Phosphorylated tau protein 181 } \\ \text { QAlb } & \text { Quotient albumin } \\ \text { QIgG } & \text { Quotient immunoglobulin G } \\ \text { QIgM } & \text { Quotient immunoglobulin M } \\ \text { SCD } & \text { Subjective cognitive decline } \\ \text { VD } & \text { Vascular disease } \\ \text { GABAAB1/2 } & \gamma \text {-Amino butyric acid A/B receptor }\end{array}$

\section{Introduction}

Autoantibody-based clinical neurological and psychiatric syndromes are a rapidly growing field in clinical neuropsychiatry and geriatric psychiatry as they often present with cognitive decline as the first or concomitant symptoms (Gibson et al. 2020; Bartels et al. 2019; Arino et al. 2016; Loane et al. 2019; Sechi and Flanagan 2019). A recent study focusing on the increasing frequency of $N$-methyl-D-aspartate receptor antibodies (NMDAR)-mediated atypical dementia (Gibson et al. 2020). In this context, atypical dementia entailing an early-onset and atypical presentation is more often reported to be associated with NMDAR autoantibodies (Gibson et al. 2020). Individual specific autoantibodies such as $\alpha$-amino-3-hydroxy-5-methyl-4-isoxazolepropionic acid receptor (AMPAR) subunit ionotropic glutamate receptor 3 (GluA3) autoantibodies (Palese et al. 2020) or contactin-associated protein-like 2 (CASPR2) autoantibodies (Guo et al. 2020) have been demonstrated in homogeneous groups of patients with cognitive impairment. They reported a high number of cancer patients with specific autoantibodies $(22.3 \%)$ with and without cognitive impairment (Bartels et al. 2019). Some patients in this cohort suffering cognitive impairment (36.9\%) had autoantibodies against NMDAR, myelin oligodendrocyte glycoprotein (MOG), pre glycine receptor alpha 1 (pre-GLRA1), glutamic acid decarboxylase 65 (GAD65), Rho GTPase-activating protein 26 (ARHGAP26) and Hu antigen (Bartels et al. 2019) suggesting a manifold illustration of specific neural autoantibodies existing in patients with cognitive impairment. No study to date has addressed the frequency of a broad spectrum of serum and CSF neural cell-surface and intracellular autoantibodies in patients with cognitive impairment in a memory clinic cohort. There have been studies addressing a wide, but different spectrum of autoantibodies than those reported to be associated with Alzheimer's disease, such as autoantibodies against the 5-hydroxytryoptamine receptor, dopamine receptor and glutamate receptors such as NMDAR (Wu et al. 2016), anti-ganglioside or anti-adenosine triphosphate synthase antibodies (Colasanti et al. 2010), or nucleosome assembly protein 1-like 3 and microtubule-associated protein 4 autoantibodies (Wang et al. 2020). We thus investigated the occurrence of various autoantibodies against cell-surface and intracellular antigens that have been only partly reported to date in patients with cognitive impairment from a memory clinic sample. Screening for autoantibodies against intracellular antigens is highly relevant diagnostic approach and therapeutic indication, as these autoantibodies are often involved in tumor immunity.

\section{Materials and methods}

\section{Patients and procedures for autoantibody search}

We consecutively enrolled a sample of 154 patients in one year between 2019 and 2020 in our retrospective and observational study. What these patients had in common was their initial presentation to a physician due to cognitive dysfunction in the memory out- and inpatient unit in the Department of Psychiatry and Psychotherapy, University Medical Center of Göttingen. We looked for autoantibodies in serum $(n=26)$ or cerebrospinal fluid (CSF) $(n=22)$ in 26 of these 154 patients (Table 1) who presented additional clinical features indicating possible underlying autoimmunity such as the "yellow flags" or "red flags" described previously (Herken and Prüss 2017). The occurrence of one "yellow flag" or "red flag" sufficed for us to look for additional specific autoantibodies in either serum or/and CSF in 26 patients. We did not search for autoantibodies in 128 patients with cognitive impairment ranging from subjective cognitive decline (SCD) to mild cognitive impairment (MCI) and dementia. Our study was conducted in accordance with the Declaration of Helsinki, and we received ethical approval for our retrospective study from our local ethics committee. 
Table 1 Demographics, psychopathology, neuropsychological and laboratory parameters of patients groups

\begin{tabular}{|c|c|c|c|c|}
\hline & $\begin{array}{l}\mathrm{ABS}+\mathrm{COG} \\
N=14\end{array}$ & $\begin{array}{l}\mathrm{ABS}-\mathrm{COG} \\
N=8\end{array}$ & $\begin{array}{l}\text { ADCOG } \\
N=9\end{array}$ & $\begin{array}{l}\text { Statistics } \\
p \text {-value }\end{array}$ \\
\hline \multicolumn{5}{|l|}{ Demographics } \\
\hline Age (years) & $68.6 \pm 3.5$ & $65.4 \pm 3.5$ & $72 \pm 3.8$ & 0.484 \\
\hline $\operatorname{Sex}(n$, female $)$ & 7 & 5 & 6 & 0.457 \\
\hline Duration of symptoms (years) & $1.8 \pm 0.6$ & $1.7 \pm 0.5$ & $3.4 \pm 1.3$ & 0.316 \\
\hline \multicolumn{5}{|l|}{ Psychopathology } \\
\hline Disorientation score $0-1,(\%$ of patients) & $0.7 \pm 0.1(64)$ & $0.4 \pm 0.2(38)$ & $0.55 \pm 0.2(56)$ & 0.906 \\
\hline Depression score $0-1$, (\% of patients) & $0.6 \pm 0.1(57)$ & $0.9 \pm 0.1(88)$ & $0.77 \pm 0.2(77)$ & 0.538 \\
\hline Suicidality score $0-1,(\%$ of patients) & $0.2 \pm 0.9(14)$ & $0.25 \pm 0.2(25)$ & $0(0)$ & 0.127 \\
\hline Anxiety score $0-1,(\%$ of patients $)$ & $0.5 \pm 0.1(43)$ & $0.62 \pm 0.2(63)$ & $0.44 \pm 0.16(44)$ & 0.854 \\
\hline OCB score $0-1,(\%$ of patients $)$ & $0.07 \pm 0.07(7)$ & $0(0)$ & $0(0)$ & 0.434 \\
\hline Delusions score $0-1,(\%$ of patients $)$ & $0.14 \pm 0.09$ & $0.13 \pm 0.11(13)$ & $0(0)$ & 0.290 \\
\hline Hallucinations score $0-1,(\%$ of patients $)$ & $0.07 \pm 0.06(7)$ & $0.13 \pm 0.11(13)$ & $0(0)$ & 0.284 \\
\hline Aggression score $0-1,(\%$ of patients $)$ & $0.3 \pm 0.11(28)$ & $0.25 \pm 0.15(25)$ & $0(0)$ & 0.519 \\
\hline Apathy score $0-1,(\%$ of patients $)$ & $0.08 \pm 0.06(7)$ & $0.13 \pm 0.12(13)$ & $0(0)$ & 0.627 \\
\hline Sleep dysfunc. score $0-1,(\%$ of patients $)$ & $0.61 \pm 0.1(57)$ & $0.42 \pm 0.17(38)$ & $0.33 \pm 0.15(33)$ & 0.171 \\
\hline Yellow flags score $0-1,(\%$ of patients) & $0.07 \pm 0.06(7)$ & $0.38 \pm 0.17(38)$ & $0(0)$ & - \\
\hline Red flags score $0-1$, ( $\%$ of patients) & $0.92 \pm 0.06(93)$ & $0.75 \pm 0.15(75)$ & $0.55 \pm 0.16(56)$ & 0.572 \\
\hline Geriatric depression score & $5.5 \pm 0.8$ & $8.6 \pm 1.6$ & $5.5 \pm 4.3$ & 0.404 \\
\hline \multicolumn{5}{|l|}{ MRI } \\
\hline Pathological temporal score & $0.28 \pm 0.1(29)$ & $0.42 \pm 0.2(38)$ & $0.57 \pm 16(44)$ & 0.575 \\
\hline Pathological extratemporal score & $0.64 \pm 0.1(64)$ & $0.42 \pm 0.2(38)$ & $0.42 \pm 15(33)$ & 0.368 \\
\hline \multicolumn{5}{|l|}{ Serum } \\
\hline CRP mg/L (pathological $>5 \mathrm{mg} / \mathrm{l}$ ) & $8.3 \pm 3.2$ & $2.7 \pm 0.4$ & $5.6 \pm 2.9$ & 0.756 \\
\hline Leukocytes $10^{3} \mu \mathrm{L}$ (Reference $\left.4-11^{3} \mu \mathrm{L}\right)$ & $7.2 \pm 0.7$ & $5.7 \pm 0.6$ & $7.7 \pm 0.3$ & 0.198 \\
\hline \multicolumn{5}{|l|}{$\mathrm{CSF}$} \\
\hline Cell count $/ \mu \mathrm{L}$ (pathological: $>5 \mu \mathrm{L}$ ) & $1.2 \pm 0.6$ & $2.5 \pm 1.3$ & $0.6 \pm 0.35$ & $<0.05$ \\
\hline Lymphocytes in \% & $73 \pm 5.4$ & $87 \pm 3.5$ & $76 \pm 3.9$ & 0.209 \\
\hline Monocytes in \% & $27 \pm 5.9$ & $12.8 \pm 3.5$ & $22 \pm 4.3$ & 0.460 \\
\hline Whole protein $\mathrm{mg} / \mathrm{L}$ & $447.4 \pm 34.9$ & $472 \pm 55$ & $389.3 \pm 27$ & 0.126 \\
\hline Albumin mg/L & $298.4 \pm 27.1$ & $317 \pm 45$ & $241.8 \pm 21$ & 0.165 \\
\hline $\mathrm{IgG} \mathrm{mg} / \mathrm{L}$ & $35.6 \pm 3.7$ & $40.6 \pm 3.8$ & $23.5 \pm 2.9$ & 0.070 \\
\hline $\operatorname{IgA} \mathrm{mg} / \mathrm{L}$ & $4.2 \pm 0.86$ & $3.8 \pm 1.2$ & $3.0 \pm 0.6$ & 0.647 \\
\hline \multicolumn{5}{|l|}{$\mathrm{CSF}$} \\
\hline $\operatorname{IgM} \mathrm{mg} / \mathrm{L}$ & $0.59 \pm 0.06$ & $0.88 \pm 0.3$ & $0.29 \pm 0.05$ & 0.062 \\
\hline QAlb \% & $7.04 \pm 0.58$ & $7.5 \pm 1.2$ & $5.9 \pm 0.53$ & 0.167 \\
\hline QIgG \% & $3.7 \pm 0.41$ & $3.9 \pm 0.6$ & $2.8 \pm 0.31$ & 0.221 \\
\hline QIgM \% & $0.81 \pm 0.16$ & $0.89 \pm 0.21$ & $0.45 \pm 0.09$ & 0.182 \\
\hline Lactat $\mathrm{mmol} / \mathrm{L}$ & $1.78 \pm 0.06$ & $1.6 \pm 0.07$ & $1.6 \pm 0.06$ & 0.751 \\
\hline Intrathecal IgG score $0-1$ ( $\%$ of patients) & $0.16 \pm 0.09(14)$ & $0.2 \pm 0.11(13)$ & $0(0)$ & 0.520 \\
\hline \multicolumn{5}{|l|}{ Neuropsychological testing } \\
\hline Semantic fluency ( $z$-value) & $-1.1 \pm 0.22$ & $0.1 \pm 0.7$ & $-0.55 \pm 0.46$ & 0.632 \\
\hline Phonematic fluency ( $z$-value) & $-0.85 \pm 0.36$ & $-0.16 \pm 0.36$ & $-0.21 \pm 0.48$ & 0.481 \\
\hline Boston naming test & $-1.01 \pm 0.34$ & $0.37 \pm 0.28$ & $-0.55 \pm 0.57$ & 0.679 \\
\hline MMSE & $24.6 \pm 1.5$ & $26.6 \pm 0.79$ & $22.1 \pm 1.7$ & 0.235 \\
\hline MMSE ( $z$-value) & $-2.8 \pm 0.68$ & $-1.97 \pm 0.62$ & $-3.3 \pm 0.6$ & 0.330 \\
\hline Verbal learning ( $z$-value) & $-2.2 \pm 0.5$ & $-1.75 \pm 0.58$ & $-3.43 \pm 0.89$ & 0.139 \\
\hline Verbal recall ( $z$-value) & $-1.9 \pm 0.3$ & $-1.69 \pm 0.49$ & $-2.26 \pm 0.51$ & 0.236 \\
\hline Word intrusions ( $z$-value) & $-0.7 \pm 0.32$ & $-0.34 \pm 0.45$ & $-0.38 \pm 0.35$ & 0.665 \\
\hline Saving words ( $z$-value) & $-2.01 \pm 0.31$ & $-1.08 \pm 0.93$ & $-0.57 \pm 0.51$ & 0.966 \\
\hline Discriminability ( $z$-value) & $-1.57 \pm 0.38$ & $-1.31 \pm 0.44$ & $-1.95 \pm 0.69$ & 0.833 \\
\hline
\end{tabular}


Table 1 (continued)

\begin{tabular}{lllll}
\hline & ABS +COG & ABS - COG & ADCOG & $\begin{array}{l}\text { Statistics } \\
N \text {-value }\end{array}$ \\
& $N=14$ & $N=8$ & $N=9$ & $p$-valu \\
\hline Visuoconstruction $(z$-value) & $-0.93 \pm 0.35$ & $-0.54 \pm 0.63$ & $-0.72 \pm 0.58$ & 0.760 \\
Figure recall $(z$-value) & $-1.94 \pm 0.36$ & $-2.7 \pm 0.52$ & $-1.9 \pm 0.56$ & 0.602 \\
Saving figures $(z$-value) & $-1.75 \pm 0.29$ & $-1.6 \pm 0.7$ & $-1.05 \pm 0.65$ & 0.919 \\
Trail making test A $(z$-value) & $-0.87 \pm 0.27$ & $-0.44 \pm 0.51$ & $-0.36 \pm 0.4$ & 0.844 \\
\hline
\end{tabular}

$A B S+C O G$ patients with autoantibodies and cognitive impairment, $A B S-C O G$ patients with cognitive impairment but no autoantibodies, $A D C O G$ Alzheimer disease patients with cognitive impairment, $C R P$ c-reactive protein, $d y s f$ dysfunction, $I g G$ immunoglobulin G, $I g M$ immunoglobulin M, MMSE Mini mental status examination, $O C B$ oligoclonal bands, $Q A l b$ quotient Albumin, $Q \operatorname{Ig} G$ quotient immunoglobulin $\mathrm{G}$, QIgM quotient immunoglobulin M

\section{Assessing cognition}

We applied the Consortium to Establish a Registry for Alzheimer's Disease (CERAD) plus testing to assess cognitive function. Patients' cognitive impairment was classified by their CERAD assessment results. A patient's cognitive impairment was termed SCD if the subject reported cognitive dysfunction, but the neuropsychological performance on CERAD ranges above -1.5 of the standard deviation (SD) on each subtest of the CERAD test armamentarium considering data normalized for age, education, and sex (Jessen et al. 2018). Cognitive performance was classified as MCI if the subject reported cognitive decline not affecting daily living abilities in line with the Jessen criteria (Jessen et al. 2018; Petersen et al. 2014) and the CERAD testing result fell below - 1.5 SD in the delayed recall subtest of the CERAD word list in respect to age, education, and sex-adapted normative data, indicating impaired episodic memory.

\section{Assessing psychopathology}

Psychopathology was classified by relying on patients' self-reports and relatives' statements from the patient letters assessing these terms: orientation, depression, anxiety, obsessive-compulsive behaviour, delusions, hallucinations, aggression, apathy, sleep dysfunction, eating abnormalities or libido. Each item was evaluated as either affected (score $=1$ ) or unaffected (score $=0$ ). Psychopathology profiles were evaluated retrospectively from patient records. We also applied the geriatric depression scale (Brink et al. 1982) to depict the severity of a depressive syndrome in elderly patients (GDS, $0-5=$ no depression, $5-10=$ mild depression, $>10=$ severe depression) before specific autoantibody testing.

\section{Group classification}

We formed three different groups of patients from our population of 154 patients. (1) From our group of patients tested for autoantibodies $(n=26)$, we formed a group of 14 patients with cognitive impairment $(n=8$ dementia, $n=5$ MCI, $n=1 \mathrm{SCD}$ ) and proof of specific autoantibodies in either serum or CSF, calling them the "ABS + COG" group. (2) Another group of 8 patients in whom we sought autoantibodies but detected no specific autoantibodies in serum or CSF revealed cognitive impairment-we refer to them as the "ABS - COG" group (ABS - COG: $n=2$ dementia, $n=6 \mathrm{MCI}$ ). (3) The third group called the "ADCOG" group (6 patients with dementia and 2 patients with MCI) served as our disease control-group consisting of 9 patients from our 154 patients with possible Alzheimer's disease (AD) due to either a typical clinical presentation according to the McKhann et al. (2011) clinical criteria in conjunction with a temporomesial atrophy pattern in MRI and/or pathological levels of molecular CSF biomarkers suggesting AD concurring with Jack et al. (2018). In these 9 patients, we tested for 4 autoantibodies due to the presence of at least one "red flag" or "yellow flag" according to Herken and Prüss (Herken and Prüss 2017). Thus, it is important to mention that we did not classify our groups by relying on the presence of "red flags" or "yellow flags". No specific autoantibodies were detected in 3 of 9 ADCOG-group patients (33\%). Anti-myelin autoantibodies were identified in one patient presenting a molecular biomarker signature suggesting Alzheimer's disease, and myelin antibodies have been reported to be associated with Alzheimer's disease (Papuc et al. 2015), thus we added that patient to our "ADCOG" group.

\section{Criteria for clinical diagnosis}

To diagnose Lewy body dementia (LBD), we applied the McKeith criteria (2017), for AD we utilized the McKhann criteria (2011), for vascular dementia (VaD) and mixed dementia (MD) we used the Gorelick et al. criteria (2011) including possible $\mathrm{VaD}$ and $\mathrm{MD}$, for Parkinson's disease dementia (PDD) we utilized the Goetz et al. criteria (2008) and to diagnose frontotemporal dementia (FTD) we exerted the Gorno Tempini et al. criteria (2011). We applied the Graus criteria to diagnose possible autoimmune encephalitis according to international guidelines (Graus et al. 2016) 
encompassing a subacute onset of (1) short-term memory abnormalities, psychiatric or mental symptoms, (2) the existence of another item (focal neurological deficit, seizures, CSF pleocytosis or MRI typical for encephalitis) and (3) the exclusion of alternative reasons for that clinical symptomatology.

\section{Autoantibody analysis}

The specific autoantibodies analyzed in the Euroimmun reference laboratory (Lübeck) were: antibodies against GAD65, Zic4, DNER/Tr, ITPR1 = Inositol 1, 4, 5-triphosphate receptor 1, Recoverin, SOX1, Ma2, Amphiphysin, CV2, Ri, Yo, $\mathrm{HuD}$ via immune line blots. We also sought autoantibodies against the following neural antigens via recombinant cellbased fluorescent technique: NMDAR, leucine-rich glioma inactivated protein 1 (LGI1), Glycin, AMPAR1/2, $\gamma$-amino butyric acid A/B receptor (GABAAB1/2), dipeptidyl-peptidase-like protein 6 (DPPX), CASPR2, potassium voltagegated channel subfamily A member 2 (KCNA2), IgLON5, MOG, and Aquaporin4.

\section{Molecular markers}

We considered a biomarker result as positive suggesting $\mathrm{AD}$ if it showed either a reduced $B$-amyloid 1-42 (Aß42) or reduced $B$-amyloid 1-42/1-40 ratio (Aß-ratio) and elevated a phosphorylated tau 181 (pTau181) or tau protein in CSF. In one patient no CSF was investigated, but $\beta$-amyloid-positron emission tomography (322 MBq Fluor-18-Florbetaben, Department of Nuclear Medicine, University Medical Center Göttingen) showed an elevated brain amyloid-load. We relied on the following reference values for our neurodegenerative biomarkers provided by the neurochemical CSF laboratory in the Göttingen University Neurological Department (tau protein: pathological $>450 \mathrm{pg} / \mathrm{ml}$, p-Tau 181 protein: pathological $>61 \mathrm{pg} / \mathrm{ml}, \mathrm{A} 342$ pathological: < $450 \mathrm{pg} / \mathrm{ml}$ and $A B$ ratio: pathological < 0.5). In addition, we enlisted the Laboratory of Clinical Neurochemistry and Neurochemical Dementia Diagnostics at University Hospital Nürnberg Erlangen to determine the $A \beta$ ratio $(A B$ ratio: pathological ${ }^{<0.5) \text {. }}$

\section{Laboratory investigations}

Other blood parameters for determination of peripheral inflammation such as C-reactive protein (CRP) and leukocytes were assessed in the University Medical Center's interdisciplinary laboratory in Göttingen. The CSF parameters immunoglobulin $\mathrm{G}$ ( $\operatorname{IgG})$, immunoglobulin A (IgGA), immunoglobulin $\mathrm{M}(\operatorname{IgM})$, albumin, and intrathecal IgG synthesis were assessed in the neurochemistry CSF laboratory in the Department of Neurology's in University Medical Center in Göttingen.

\section{Neuroimaging}

Temporal and extratemporal magnetic resonance imaging (MRI) were performed either in the University Medical Center Göttingen's Neuroradiology Department with a 1.5 T MRI (Siemens AvantoFit) or off-site in a neuroradiologic center in Göttingen. We developed a score describing the degree of affection of the temporal and extratemporal brain regions (Score $=0$ means unaffected, score 1 means affected). Furthermore, we documented MRI abnormalities between groups.

\section{Statistics}

Descriptive statistics were used to analyze the frequency of autoantibodies and other demographic parameters in our cohort. ANOVA was used to compare age in years, duration of symptoms in years, sex, psychopathology scores $(0-1)$, GDS values, MMSE values, MRI scores (0-1), CSF parameters [(intrathecal IgG synthesis (score $=0$ not present, score $1=$ present)] and CSF neurodegenerative markers between groups (ABS + COG, ABS - COG- and ADCOG group). Furthermore, LSD post hoc tests with Bonferroni correction were used for evaluate differences between groups (ABS + COG, ABS - COG- and ADCOG group). Mann-Whitney $U$-tests were utilized to compare patients with different $\mathrm{MCI}$ etiologies to those with diverse dementia etiologies. A $p$-level of $p^{<} 0.05$ was considered significant.

\section{Results}

\section{Basic memory clinic population}

The symptoms of cognitive dysfunction in 154 patients were classified as subjective cognitive decline (SCD), mild cognitive impairment (MCI) or dementia according to the aforementioned criteria. The number of patients with dementia with diverse diagnoses does not differ from that of patients with MCI due to diverse diagnoses (Fig. 1, Mann-Whitney $U$-test $p=0.51$ ). We conducted no specific autoantibody tests in 128 patients: these patients suffered cognitive impairment due to the following suspected diagnoses: vascular disease (VaD) $(n=1 \mathrm{SCD}, n=14 \mathrm{MCI}$ (VaMCI) and $n=5$ dementia), neurodegenerative disease [AD: $n=5 \mathrm{MCI}$ (MCI with Alzheimer's disease etiology), $n=14$ dementia (ADD); LBD: $n=2 \mathrm{MCI}, n=12$ dementia; PDD: $n=1$ MCI, $n=1$ dementia; FTD: $n=5 \mathrm{MCI}, n=3$ dementia], mixed etiology ( $n=3 \mathrm{MCI}, n=31$ dementia) or other etiologies ( $n=4 \mathrm{SCD}, n=24 \mathrm{MCI}$ and $n=3$ with 


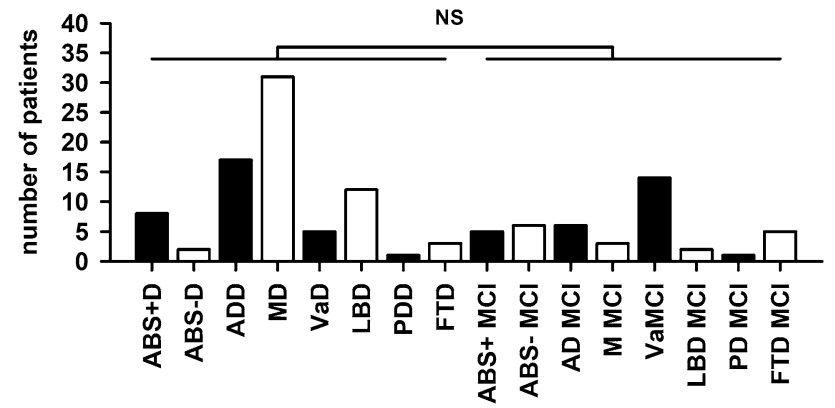

Fig. 1 Memory clinic patient cohort. We detected no significant differences between the numbers of patients with different diagnoses and those with dementia and those with mild cognitive impairment (MCI). $A B S+D$ autoantibody-positive with dementia, $A B S-D$ autoantibody-negative with dementia, $A D$ Alzheimer's disease, $M D$ mixed dementia, $V a D$ vascular dementia, $L B D$ Lewy body dementia, $P D D$ Parkinson's disease dementia, FTD frontotemporal dementia, $A B S+M C I$ autoantibody-positive patients with mild cognitive impairment, $A B S-M C I$ autoantibody-negative patients without mild cognitive impairment, $A D M C I$ Mild cognitive impairment with Alzheimer etiology, $M M C I$ mixed etiology of mild cognitive impairment, $N S$ non significant, VaMCI vascular disease with mild cognitive impairment, $L B D M C I$ Lewy body disease with mild cognitive impairment, $P D M C I$ Parkinson's disease with mild cognitive impairment, FTD $M C I$ frontotemporal disease with mild cognitive impairment

dementia). All patients are depicted cross-sectionally; no follow-ups have occurred so far.

\section{Clinical, psychopathological, neuropsychological characteristics of groups}

Sex, age, and years of disease duration did not differ between patient groups (ABS + COG, ABS - COG, ADCOG, Table 1). We detected no differences between groups in their psychiatric presentation regarding their disorientation, obsessive-compulsive behaviour, depression, anxiety, delusions, hallucinations, suicidality, aggression, apathy, sleep, eating abnormalities and libido score (ANOVA, n.s., Table 1). Neuropsychological functions assessed by the CERAD Plus instrument (semantic and phonematic word fluency, learning and consolidation of verbal and figural material, psychomotoric processing speed as well as visuoconstruction, naming) did not differ in their $z$-values between groups in any cognitive subdomain (ANOVA: $F 13.3, p=0.21$, Table 1 ). For other clinical characteristics as comorbidities see Tables 1 and 2 .

\section{Autoimmune indicators of groups}

We determined autoantibodies in 26 patients due their presenting $\geq 1$ indicator of autoimmunity ["red flag" or "yellow flag"]. In 12/14 of (86\%) ABS + COG group patients, we detected one $\geq$ "red flag" comprising another autoimmune disorder $(n=2)$, tremor $(n=2)$, paresthesia $(n=1)$, newonset headache $(n=2)$, focal neurological disease $(n=3)$, severe cognitive dysfunction unexplained by another diagnosis $(n=3)$, autonomic dysfunction $(n=2)$, whereas $2 / 14$ (14\%) presented one "yellow flag" (psychomotor symptoms $n=2)$. The ABS-COG group contained 6/8 (75\%) of patients with one "red flag" (infectious prodrom with fever $n=1$, seizures $n=2$, paresthesia $n=1$, decreased level of consciousness $n=1$, new-onset headache $n=1)$ and 3/8 (38\%) patients with one "yellow flag" (dynamic course $n=1$, personality dynamic changes $n=1$, fluctuating psychopathology $n=1$ ). Furthermore, we identified red flags in 5/9 (56\%) ADCOGgroup patients (focal neurological disease $n=2$, new-onset headache $n=1$, severe cognitive dysfunction not attributable to any other diagnosis $n=1$, tumor $n=1$ ).

\section{Serum and cerebrospinal fluid autoantibodies}

We investigated serum and/or CSF autoantibodies in 26 of 154 (17\%) of patients (Tables 2, 3). In 15 of 26 (58\%) patients, we detected serum $(n=15)$ or CSF $(n=4)$ autoantibodies (Table 1). However, we cannot rule out that patients lacking autoimmune indicators whom we do not screen for autoantibodies might have possessed specific detectable autoantibodies. AD dementia was later assumed in one of those patients with positive autoantibodies (serum myelin antibodies). Our 14 ABS + COG patients did not receive a concomitant cognitive-impairment diagnosis due to major cerebrovascular disease. The specific autoantibodies we detected in 14 patients were: $n=1$ CASPR 2 abs, $n=1$ CV2, $n=3$ Recoverin, $n=2$ KCNA2, $n=2$ Glycin, $n=1$ Yo, $n=1$ ITPR $1, n=1$ IgLON5 and $n=1$ Titin in serum as well as $n=1$ Yo abs, $n=1$ IgLON5 abs and $n=1$ MOG abs in CSF. We detected 11 different autoantibodies in serum and CSF in 15 patients with autoantibodies, thereby revealing the heterogeneous spectrum of specific autoantibodies that patients with cognitive impairment may exhibit. Antibodies against cell-surface and intracellular antigens were found in 7/14 (50\%) of ABS + COG patients, respectively (see Table 3 for frequencies of specific autoantibodies). Furthermore, we detected unspecific neuropil antibodies in one patient's cerebrum, thalamus, and in hippocampus in the serum and CSF. In contrast, in 11 of 26 patients (42\%, Table 3) we identified no antibodies in either serum or CSF. Possible autoimmune encephalitis was diagnosed in 8 of those 14 patients (57\%) with serum and/or CSF 
Table 2 Antibody characteristics, drugs, and comorbidities of patient groups

\begin{tabular}{|c|c|c|c|}
\hline & $\mathrm{ABS}+\mathrm{COG} N(\%)$ & ABS - COG $N(\%)$ & ADCOG $N(\%)$ \\
\hline \multicolumn{4}{|l|}{ Cell-surface autoantibody } \\
\hline CASPR2 Serum & $1(7.1 \%)$ & - & - \\
\hline Glycin Serum & $2(14.3 \%)$ & - & - \\
\hline IgLON5 CSF & $1(7.1 \%)$ & - & - \\
\hline IgLON5 Serum & $1(7.1 \%)$ & - & - \\
\hline KCNA2 Serum & $1(7.1 \%)$ & - & - \\
\hline Myelin Serum & - & - & $1(7.1 \%)$ \\
\hline MOG CSF & $1(7.1 \%)$ & - & - \\
\hline \multicolumn{4}{|l|}{ Intracellular antibody } \\
\hline CV2 Serum & $1(7.1 \%)$ & - & - \\
\hline ITPR1 Serum & $1(7.1 \%)$ & - & - \\
\hline Recoverin Serum & $2(14.3 \%)$ & - & - \\
\hline Titin Serum & $1(7.1 \%)$ & - & - \\
\hline Yo CSF & $1(7.1 \%)$ & - & - \\
\hline Yo Serum & $2(7.1 \%)$ & - & - \\
\hline \multicolumn{4}{|l|}{ Unspecific neuropil binding } \\
\hline CSF Hipp, Thalamus, Cortex & $1(7.1 \%)$ & - & - \\
\hline Serum Hipp, Thalamus, Cortex & $1(7.1 \%)$ & - & - \\
\hline \multicolumn{4}{|l|}{ Psychiatric comorbidity } \\
\hline Agoraphobia - panic disorder & $1(7.1 \%)$ & $0(0 \%)$ & $0(0 \%)$ \\
\hline Agoraphobia + panic disorder & $1(7.1 \%)$ & $(0 \%)$ & $0(0 \%)$ \\
\hline Bipolar disorder & $1(7.1 \%)$ & $2(25 \%)$ & $0(0 \%)$ \\
\hline Cyclothymia & $1(7.1 \%)$ & $0(0 \%)$ & $0(0 \%)$ \\
\hline Major depressive episode & $3(38.5 \%)$ & $2(25 \%)$ & $2(22 \%)$ \\
\hline Minor depressive episode & $2(14.3 \%)$ & $1(12.5 \%)$ & $1(11 \%)$ \\
\hline Nicotine dependency & $1(7.1 \%)$ & $0(0 \%)$ & $0(0 \%)$ \\
\hline Obsessive-compulsive disorder & $1(7.1 \%)$ & $0(0 \%)$ & $0(0 \%)$ \\
\hline Posttraumatic stress disorder & $0(0 \%)$ & $1(12.5 \%)$ & $0(0 \%)$ \\
\hline Somatoform autonomic disorder & $1(7.1 \%)$ & $0(0 \%)$ & $0(0 \%)$ \\
\hline \multicolumn{4}{|l|}{ Neurologic comorbidity } \\
\hline Atypical restless leg syndrome & $1(7.1 \%)$ & $0(0 \%)$ & $0(0 \%)$ \\
\hline Cerebral ischemic attacks & $1(7.1 \%)$ & $0(0 \%)$ & $0(0 \%)$ \\
\hline Disc prolapse & $0(0 \%)$ & $2(25 \%)$ & $0(0 \%)$ \\
\hline Meningioma & $1(7.1 \%)$ & $0(0 \%)$ & $0(0 \%)$ \\
\hline Migraine & $0(0 \%)$ & $1(12.5 \%)$ & $0(0 \%)$ \\
\hline Major cerebrovascular disease & $0(0 \%)$ & $0(0 \%)$ & $1(11 \%)$ \\
\hline Post herpes encephalitis & $0(0 \%)$ & $1(12.5 \%)$ & $0(0 \%)$ \\
\hline Neuropathy & $1(7.1 \%)$ & $0(0 \%)$ & $1(11 \%)$ \\
\hline Spinal canal stenosis & $0(0 \%)$ & $0(0 \%)$ & $1(11 \%)$ \\
\hline Structural epilepsy & $1(7.1 \%)$ & $1(12.5 \%)$ & $0(0 \%)$ \\
\hline Tension-type headache & $2(14.3 \%)$ & $0(0 \%)$ & $0(0 \%)$ \\
\hline Temporal lobe epilepsy & $2(14.3 \%)$ & $0(0 \%)$ & $0(0 \%)$ \\
\hline Tremor & $1(7.1 \%)$ & $0(0 \%)$ & $0(0 \%)$ \\
\hline \multicolumn{4}{|c|}{ Immunologic or autoimmune comorbidity } \\
\hline Autoimmunthyreoiditis & $0(0 \%)$ & $1(12.5 \%)$ & $0(0 \%)$ \\
\hline Colitis ulcerosa & $0(0 \%)$ & $1(12.5 \%)$ & $0(0 \%)$ \\
\hline Monoclonal gammopathy & $1(7.1 \%)$ & $0(0 \%)$ & $0(0 \%)$ \\
\hline IgM Kappa proteinemia & $1(7.1 \%)$ & $0(0 \%)$ & $0(0 \%)$ \\
\hline Secondary $\operatorname{IgG}$ deficiency & $1(7.1 \%)$ & $0(0 \%)$ & $0(0 \%)$ \\
\hline \multicolumn{4}{|l|}{ Psychopharmacologic drugs } \\
\hline Antidementiva & $4(21 \%)$ & $0(0 \%)$ & $7(78 \%)$ \\
\hline
\end{tabular}


Table 2 (continued)

\begin{tabular}{llll}
\hline & ABS +COG $N(\%)$ & ABS - COG N (\%) & ADCOG N (\%) \\
\hline Antidepressants & $8(57 \%)$ & $5(63 \%)$ & $2(22 \%)$ \\
Anxiolytics & $1(7.1 \%)$ & $0(0 \%)$ & $0(0 \%)$ \\
Mood stabilizer & $1(7.1 \%)$ & $0(0 \%)$ & $1(11 \%)$ \\
Neuroleptics & $1(7.1 \%)$ & $1(12.5 \%)$ & $1(11 \%)$ \\
Immunotherapy & & & \\
Corticosteroids & $4(27 \%)$ & $1(12.5 \%)$ & $0(0 \%)$ \\
MRI abnormalities & & & $0(0 \%)$ \\
Enlarged limbic structures & $0(0 \%)$ & $0(0 \%)$ & $2(22 \%)$ \\
Generalized cortical atrophy & $7(50 \%)$ & $0(0 \%)$ & $2(22 \%)$ \\
Altered limbic gray matter & $3(21 \%)$ & $0(0 \%)$ & $2(22 \%)$ \\
Hippocampal sclerosis & $3(21 \%)$ & $0(0 \%)$ & $3(33 \%)$ \\
Localized brain atrophy & $7(50 \%)$ & $3(38 \%)$ & $1(11 \%)$ \\
Macroangiopathy & $1(7.1 \%)$ & $0(0 \%)$ & $3(33 \%)$ \\
Microangiopathy & $8(57 \%)$ & $3(38 \%)$ & $2(22 \%)$ \\
Ventricle enlargement & $3(21 \%)$ & $0(0 \%)$ & \\
Malignancy & $1(7.1 \%)$ & $0(0 \%)$ & $0(0 \%)$ \\
Bladder carcinoma & $1(7.1 \%)$ & $0(0 \%)$ & $0(0 \%)$ \\
Colon carcinoma & $0(0 \%)$ & $1(12.5 \%)$ & $1(11 \%)$ \\
Mammary carcinoma & $0(0 \%)$ & $1(12.5 \%)$ & $0(0 \%)$ \\
Melanoma & $0(0 \%)$ & $0(0 \%)$ & $1(11 \%)$ \\
Thyroid carcinoma & & & \\
\hline
\end{tabular}

$A B S+C O G$ patients with autoantibodies and cognitive impairment, $A B S-C O G$ patients with cognitive impairment but no autoantibodies, $A D C O G$ Alzheimer disease patients with cognitive impairment, CASPR2 contactin-associated protein like 2, Hipp hippocampus, IgM immunoglobulin M, ITPR1 Inositol 1,4,5-triphosphate receptor $1, M O G$ myelin oligodendrocyte glycoprotein, $N$ number

autoantibodies and in one patient of those with no serum or CSF autoantibodies (12.5\%). We thus diagnosed possible autoimmune encephalitis in $5.8 \%$ of the patients in our entire memory clinic sample. Furthermore, 5 of 14 antibody-positive patients (36\%) fulfilled the criteria for a probable autoimmune-based cognitive impairment according to Hansen et al. (Hansen et al. 2020a). See Tables 1 and 2 for MRI abnormalities, tumors, and drug history of patient groups.

\section{Molecular markers of groups}

We detected no significant differences in CSF Tau, pTau181, and $A \beta 40$ between groups $(\mathrm{ABS}+\mathrm{COG}$, ABS - COG, ADCOG). However, a significant difference in the $\mathrm{A} B 42 \mathrm{CSF}$ content emerged between groups (ABS + COG, ABS - COG, ADCOG) (ANOVA: $F=4.06, p<0.05$, Fig. 2). CSF Aß42 was significantly more reduced in the ADCOG than the ABS + COG group, confirming one typical positive biomarker for diagnosing AD (Post Hoc LSD test: $p<0.05$, Fig. 2). In addition, the Aß42/40 ratio was lower in ADCOG patients confirming $\mathrm{AD}$, but not in the ABS + COG or ABS - COG (ANOVA: $F=4.06, p<0.05$, Fig. 2).

\section{Laboratory results of groups}

CSF data are depicted in Table 1. Intrathecal IgG synthesis was observed in $14 \%$ of $\mathrm{ABS}+\mathrm{COG}$ and in $13 \%$ of ABS - COG patients, whereas the ADCOG patients revealed no intrathecal IgG synthesis. CSF cell counts differed significantly between groups $(\mathrm{ABS}+\mathrm{COG}, \mathrm{ABS}-\mathrm{COG}$, ADCOG) (ANOVA: $F=4.1, p<0.05$ ), but on average, no pleocytosis was observed in any group $(\mathrm{ABS}+\mathrm{COG}$, ABS - COG, ADCOG), and the LSD post hoc tests demonstrated no significant group differences between disease groups (ABS + COG, ABS - COG, ADCOG). Our other CSF data, such as lymphocytes in \%, monocytes in $\%$, whole protein, albumin, $\operatorname{IgG}, \operatorname{IgA}, \operatorname{IgM}$, the quotient of albumin in $\%$, the quotient of $\operatorname{IgG}, \operatorname{IgM}, \operatorname{IgA}$ in $\%$, lactate, and the presence of intrathecal IgG synthesis score did not differ between groups either (ABS + COG, ABS - COG, ADCOG). We observed no correlation between a blood-brain barrier disturbance or the albumin quotient and the level of cognitive impairment and psychopathological profile.

\section{Immunotherapy}

The majority of ABS + COG patients (but only one ABS - COG group patient) underwent immunotherapy. $50 \%$ 
Table 3 Specification of cohort following autoantibody testing

\begin{tabular}{ll}
\hline Parameters & $N(\%)$ \\
\hline Patients in whom we sought autoantibodies, $N=26$ & \\
Hit rate for serum and CSF autoantibodies & $15(58)$ \\
Hit rate for positive serum autoantibodies & $15(58)$ \\
Hit rate for positive CSF autoantibodies & $4(15)$ \\
Positive CSF autoantibody result & $4(15)$ \\
Positive serum autoantibody result & $15(58)$ \\
Cell-surface autoantibodies serum and CSF & $7(27)$ \\
Intracellular autoantibodies serum and CSF & $7(27)$ \\
Cell-surface autoantibodies serum & $6(23)$ \\
Intracellular autoantibodies serum & $6(23)$ \\
Cell-surface autoantibodies CSF & $2(8)$ \\
Intracellular autoantibody CSF & $1(4)$ \\
Negative serum and CSF autoantibody result & $11(42)$ \\
ABS + COG patients, $N=14$ & \\
Cell-surface autoantibodies serum and CSF & $7(50)$ \\
Intracellular autoantibodies serum and CSF & $7(50)$ \\
Cell-surface autoantibodies serum & $6(43)$ \\
Intracellular autoantibodies serum & $6(43)$ \\
Cell-surface autoantibodies CSF & $2(14)$ \\
Intracellular autoantibody CSF & $1(7)$ \\
Unspecific neuropil antibody CSF & $1(7)$ \\
\hline
\end{tabular}

$A B S+C O G$ patients with autoantibodies and cognitive impairment, $C S F$ cerebrospinal fluid, $N$ number

of $\mathrm{ABS}+\mathrm{COG}$ patients with CSF autoantibodies were given intravenous methylprednisolone (Table 1). The others did not receive immunotherapy for different reasons (no presentation, immunotherapy refused). $6 / 8$ (75\%) of patients with autoantibody-positive possible autoimmune encephalitis and $3 / 5(60 \%)$ patients with probable autoimmune based cognitive impairment received intravenous methlyprednisolone. Only one patient with autoantibody-negative encephalitis underwent methylprednisolone therapy.

\section{Discussion}

Neural cell-surface and intracellular autoantibodies are detected in 15 of 26 (58\%) of memory-clinic patients with potential indicators of autoimmunity and cognitive impairment varying from mild cognitive impairment to dementia. We are the first to report the relatively broad and heterogeneous autoantibody spectrum in autoantibody-positive patients presenting 11 specifically detectable autoantibodies and suffering cognitive impairment ranging from MCI to dementia. The high rate of autoantibody detection (58\%) in our cohort was due to preselected patients via the presence of possible autoimmune indicators according to the classification of Herken and Prüss (2017). Nevertheless, we do not know the frequency of specific autoantibodies in our 128 patient sample in whom we did not seek antibodies. Our retrospective survey revealed no specific psychopathology and laboratory profile (apart from a reduced $A \beta 42$ and $A \beta 42 / 40$ ratio in the ADCOG, but not in the ABS + COG and ABS - COG groups) that clearly differentiates autoantibody-mediated cognitive impairment from biological Alzheimer's disease.

\section{Spectrum of specific autoantibodies associated with cognitive impairment}

We were unable to confirm Gibson's findings (2020), namely the higher frequency of NMDAR autoantibodies in patients with atypical dementia in our cohort of autoantibody-positive patients with cognitive dysfunction. Surprisingly, certain autoantibodies have never yet been associated with cognitive impairment, such as the Recoverin antibodies known to mediate autoimmune retinopathy (Oporto Caroca and Oporto Caroca 2019). Frontal atrophy probably due to a neurodegenerative process after an inflammatory state has been described in conjunction with Yo autoantibodies by a study of Endres et al. (2015). Other autoantibodies such as CASPR2, IgLON5, Glycin, and MOG have been reported to be associated with cognitive dysfunction in individual cases and case series (Hansen et al. 2020b; Baba et al. 2019; Swayne et al. 2018; Van Sonderen et al. 2016). In contrast, ITPR1 and KCNA2 autoantibodies have so far not been reported in patients with cognitive dysfunction as the predominant clinical syndrome. The autoantibodies in our cohort patients represent a continuum from possible autoimmune encephalitis to cognitive dysfunction as a clinically-isolated syndrome associated with autoantibodies but not revealing any other evidence of autoimmune encephalitis. The cognitive impairment could be due to an encephalopathy involving functionally disturbed brain function due to interfering synaptic protein autoantibodies such as CASPR2, KCNA2 or glycin autoantibodies in strategically cognition-relevant structures like the hippocampus. Indeed, glycin receptors are expressed in the hippocampus, and are responsible for inhibitory transmission. Glycin autoantibodies in the hippocampus might explain why the memory function in these patients is disturbed, through increased neuronal excitation due to less inhibitory tone. Neural transmission is affected by synaptic autoantibodies, as are IgLON5 autoantibodies, which can result in increased tau deposits in cognition-relevant areas such as the hippocampal and entorhinal regions as demonstrated recently in a patient (Erro et al. 2019). The broader impairment of neuronal networks contributing to cognition can be assumed due to the ubiquitous brain localization of MOG antibodies, as these autoantibodies induce experimental autoimmune encephalitis (Wegener 
Fig. 2 Molecular markers of groups. The Aß1-142/1-40 ratio and $A ß 1-42$ were significantly reduced in Alzheimer's disease patients with cognitive impairment (ADCOG) when compared with those patients with cognitive impairment and autoantibodies (ABS + COG) as well as without autoantibodies (ABS - COG). The dashed red lines indicate the cut-off laboratory values for each molecular marker. $* p<0.05$, ANOVA. A $\beta 1$-40 Beta Amyloid 40, A $\beta 1$ 42 Beta Amyloid 42, NS non significant, $p$-tau 181 phosphorylated tau protein 181
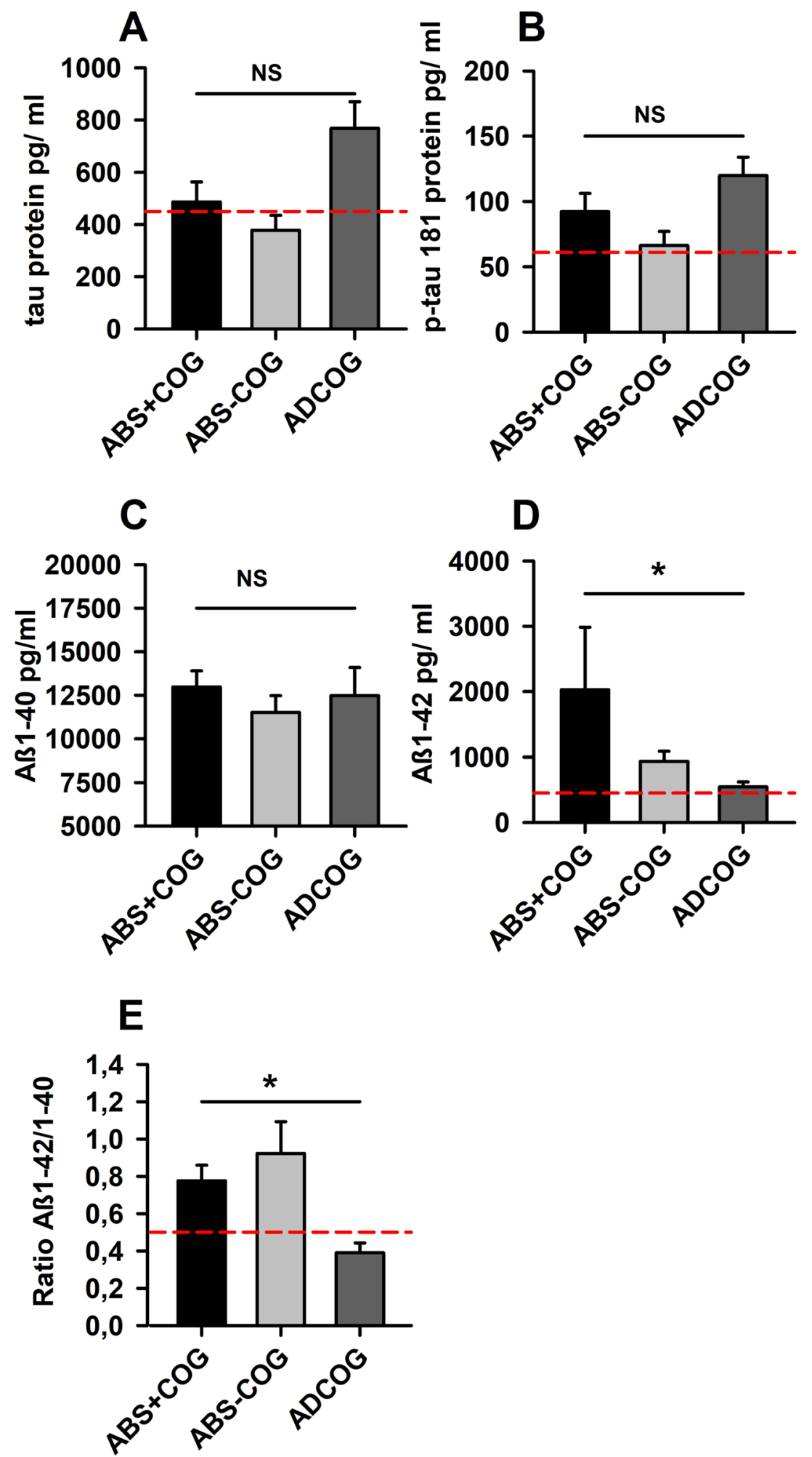

and Panzer 2020). The specific interaction between relevant brain regions in cognition [such as the cerebellum and limbic system termed limbic cerebellum (Schmahmann 2019)] might be impaired by the accumulation of specific autoantibodies such as ITPR 1 antibodies known to induce a form of autoimmune cerebellar ataxia (Weihua et al. 2019). 


\section{Markers of neurodegeneration and autoantibodies associated with cognitive impairment}

Our findings show that $\mathrm{A} ß 42$ and the $\mathrm{A} \beta 42 / 40$ ratio are pathogenic markers in Alzheimer's disease, but not in cognitive impairment associated with autoantibodies, thus confirming prior knowledge. Autoantibody-associated cognitive decline did not lead to a $\beta$-amyloidopathy-related neurodegenerative process. We were surprised to observe that total tau protein was not elevated in the ABS + COG group, although previous studies have reported elevated tau protein in patients suffering from antibody-positive autoimmune encephalitis (Constantinescu et al. 2016). As our ABS + COG subgroup only contains some patients with autoimmune encephalitis, these findings might indicate a distinction between autoantibody-associated isolated cognitive dysfunction and autoimmune encephalitis in their degree of secondary neurodegeneration. We detected no total tau protein elevation in the majority of $\mathrm{ABS}+\mathrm{COG}$ patients, indicating no further neurodegenerative process like that observed in rapidly progressing Alzheimer's disease in apoliprotein E (APOE) ع4-carriers (Wattmo et al. 2020).

\section{Pathogenic role of autoantibodies}

The cognitive impairment in 9 of 26 (35\%) of our patients tested for autoantibodies is likely caused by possible autoimmune encephalitis. In another 5 of 14 (36\%) antibodypositive patients, we diagnosed a probable autoimmunebased psychiatric syndrome (for review see Hansen et al. 2020a) presenting as cognitive dysfunction. Only one patient presented no discernable autoimmune etiology. The pathological significance of serum autoantibodies in conjunction with no other indications of an underlying immunopathology (verified by additional diagnostics) is unclear. However, and although other hints indicating autoimmunity are present, the relevance of these serum autoantibodies is often incompletely understood. For example, autoantibodies might be an epiphenomenon not related to the main pathophysiology such as cellular immunity, i.e., cytotoxic CD8 + T-cells (Langenbruch et al. 2020); GAD65 autoantibodies themselves do not represent a major part of the autoimmunity process, as intrathecal GAD65 antibody production is often unproven (for review see Graus et al. 2020). Other autoantibodies, such as those against membrane surface antigens, often play a relevant role in immunopathology, such as NMDAR autoantibodies (Malviya et al. 2017). We thus need additional novel biological markers for those patients with cognitive dysfunction who do not reveal autoimmune indicators according to autoimmune encephalitis or autoimmunebased psychiatric syndromes guidelines (Graus et al. 2016; Hansen et al. 2020a). This point is further corroborated by the fact that serum autoantibodies alone might occur in healthy humans that do not reveal cognitive decline, as a study by Levin demonstrated (Levin et al. 2010). In addition, autoantibodies may not even contribute to the disease progress and pathophysiology, as they can play a protective role, i.e., specific autoantibodies in Alzheimer's disease (Sim et al. 2020). Another relevant issue is that the presence of serum autoantibodies seems to depend on the blood-brain barrier's integrity, as its breakdown is accompanied by the numerous and highly varied human brain reactive autoantibodies targeting membrane proteins (Levin et al. 2010). Thus, it is reasonable to presume a transient blood-brain barrier breakdown as a precondition in those patients with brain-reactive serum autoantibodies, although we discerned no relationship between the occurrence of blood-brain barrier disturbances and the albumin quotient in CSF and the degree of cognitive impairment. Taken together, it remains unclear whether there is a role and if so, what the pathogenic role is of various proven serum autoantibodies in patients. What this question raises, in particular, is whether other autoimmune indicators are lacking. CSF analysis including specific autoantibody analysis is, therefore, the best approach for later therapeutic decisions.

\section{Limitations}

Our cohort is too small to draw any practicable conclusions. Furthermore, our cohort is heterogeneous, thus precluding conclusions on the autoantibody frequency of individual autoantibodies in cohorts presenting cognitive impairment. Furthermore, the frequency of autoantibodies detected in serum and CSF only enables us to estimate the potential frequency within our entire memory cohort, as we only tested those patients presenting possible autoimmunity due to indicators, and not all patients with cognitive impairment. Moreover, it is unclear whether these potential autoimmune indicators really do indicate those patients with possible underlying autoantibodies. Further systematic research is required in different groups suffering cognitive impairment to clarify this issue. The wide variability of the 11 autoantibodies we detected in 15 patients might argue for the plethora of autoantibodies involved in several types of cognitive dysfunction. But this might also imply that specific autoantibodies play no pathogenic role.

\section{Conclusions}

Our study in a memory cohort examined how often autoantibodies can be discerned in patients with cognitive dysfunction revealing additional hints for autoimmunity. The fact that we detected autoantibodies in $58 \%$ of patients suffering cognitive impairment (among those whom we had screened for autoantibodies) suggests an underestimated phenomenon 
that memory clinic staffs should be aware to diagnose and treat patients promptly and adequately. Furthermore, we cannot exclude that the autoantibody frequency is even higher, given that we did not test for specific autoantibodies in all patients. Our results are promising for the future establishment of testing serum and CSF autoantibodies in patients with cognitive dysfunction and indicators of autoimmunity. In addition, as autoimmune indicators are detected in patients with and without antibodies as well as in those with Alzheimer's disease, further research is required to help discover sensitive clinical and molecular biomarkers of autoimmunity besides autoantibodies as early possible indicators of autoimmune-related cognitive impairment.

Acknowledgements JW is supported by an Ilídio Pinho professorship, iBiMED (UIDB/04501/2020) at the University of Aveiro, Portugal.

Author contributions NH conceived the study and wrote the manuscript. BM, CT, IZ, WS and JW revised the manuscript for important intellectual content.

Funding Open Access funding enabled and organized by Projekt DEAL.

Data availability Data is available.

\section{Compliance with ethical standards}

Conflict of interest The authors have no conflict of interest to declare.

Open Access This article is licensed under a Creative Commons Attribution 4.0 International License, which permits use, sharing, adaptation, distribution and reproduction in any medium or format, as long as you give appropriate credit to the original author(s) and the source, provide a link to the Creative Commons licence, and indicate if changes were made. The images or other third party material in this article are included in the article's Creative Commons licence, unless indicated otherwise in a credit line to the material. If material is not included in the article's Creative Commons licence and your intended use is not permitted by statutory regulation or exceeds the permitted use, you will need to obtain permission directly from the copyright holder. To view a copy of this licence, visit http://creativecommons.org/licenses/by/4.0/.

\section{References}

Ariño H, Armangué T, Petit-Pedrol M, Sabater L, Martinez-Hernandez E, Hara M, Lancaster E, Saiz A, Dalmau J, Graus F (2016) AntiLGI1-associated cognitive impairment: presentation and longterm outcome. Neurology 87:759-765. https://doi.org/10.1212/ WNL.0000000000003009

Baba T, Shinoda K, Watanabe M, Sadashima S, Matsuse D, Isobe N et al (2019) MOG antibody disease manifesting as progressive cognitive deterioration and behavioral changes with primary central nervous system vasculitis. Mult Scler Relat Disord 30:48-50. https://doi.org/10.1016/j.msard.2019.01.053

Bartels F, Strönisch T, Farmer K, Rentzsch K, Kiecker F, Finke C (2019) Neuronal autoantibodies associated with cognitive impairment in melanoma patients. Ann Oncol 30:823-829. https ://doi.org/10.1093/annonc/mdz083

Brink TL, Yesavage JA, Lum O et al (1982) Screening tests for geriatric depression. Clin Gerontol 1:37-43

Colasanti T, Barbati C, Rosano G, Malorni W, Ortona E (2010) Autoantibodies in patients with Alzheimer's disease: pathogenetic role and potential use as biomarkers of disease progression. Autoimmun Rev 9:807-811 (Erratum in: Autoimmun Rev 11:374. pmid: 20656067)

Constantinescu R, Krýsl D, Bergquist F, Andrén K, Malmeström C, Asztély F et al (2016) Cerebrospinal fluid markers of neuronal and glial cell damage to monitor disease activity and predict long-term outcome in patients with autoimmune encephalitis. Eur J Neurol 23:796-806. https://doi.org/10.1111/ene.12942

Endres D, Perlov E, Stich O, Meyer PT, Lützen N, Tebartz van Elst L (2015) Case report: low-titre anti-Yo reactivity in a female patient with psychotic syndrome and frontoparieto-cerebellar atrophy. BMC Psychiatry. 15:112. https://doi.org/10.1186/s1288 8-015-0486-x

Erro ME, Sabater L, Martínez L, Herrera M, Ostolaza A, García de Gurtubay I, Tuñón T, Graus F, Gelpi E (2019) Anti-IGLON5 disease: a new case without neuropathologic evidence of brainstem tauopathy. Neurol Neuroimmunol Neuroinflamm 7:e651

Gibson LL, McKeever A, Cullen AE, Nicholson TR, Aarsland D, Zandi MS, Pollak TA (2020) Neuronal surface autoantibodies in dementia: a systematic review and meta-analysis. J Neurol. https://doi. org/10.1007/s00415-020-09825-0

Goetz CG, Emre M, Dubois B (2008) Parkinson's disease dementia: definitions, guidelines, and research perspectives in diagnosis. Ann Neurol 64:S81-92. https://doi.org/10.1002/ana.21455

Gorelick PB, Scuteri A, Black SE, Decarli C, Greenberg SM, Iadecola C et al (2011) American Heart Association Stroke Council, Council on Epidemiology and Prevention, Council on Cardiovascular Nursing, Council on Cardiovascular Radiology and Intervention, and Council on Cardiovascular Surgery and Anesthesia. Vascular contributions to cognitive impairment and dementia: a statement for healthcare professionals from the american heart association/ american stroke association. Stroke 42:2672-2713. https://doi. org/10.1161/STR.0b013e3182299496

Gorno-Tempini ML, Hillis AE, Weintraub S, Kertesz A, Mendez M, Cappa SF et al (2011) Classification of primary progressive aphasia and its variants. Neurology 76:1006-1014. https://doi. org/10.1212/WNL.0b013e31821103e6

Graus F, Titulaer MJ, Balu R, Benseler S, Bien CG, Cellucci T et al (2016) A clinical approach to diagnosis of autoimmune encephalitis. Lancet Neurol 15:391-404. https://doi.org/10.1016/S1474 $-4422(15) 00401-9$

Graus F, Saiz A, Dalmau J (2020) GAD antibodies in neurological disorders-insights and challenges. Nat Rev Neurol 16:353-365. https://doi.org/10.1038/s41582-020-0359-x

Guo YP, Li XY, Liu HF, Zhang M, Shi L, Zhao XJ et al (2020) Clinical analysis of 7 cases with anti-Caspr2 antibody-associated autoimmune encephalitis. Zhonghua Yi Xue Za Zhi 100:513-515. https ://doi.org/10.3760/cma.j.issn.0376-2491.2020.07.007

Hansen N, Hirschel S, Stöcker W, Manig A, Falk HS, Ernst M et al (2020b) Figural memory impairment in conjunction with neuropsychiatric symptoms in IgLON5 antibody-associated autoimmune encephalitis. Front Psychol 11:576. https://doi.org/10.3389/ fpsyt.2020.00576

Hansen N, Lipp M, Vogelgsang J, Vukovich R, Zindler T, Lüdecke D et al (2020a) Autoantibody-associated psychiatric symptoms and syndromes in adults: a narrative review and proposed diagnostic approach. Brain Behav Immunity Health 9:100154

Herken J, Prüss H (2017) Red Flags: clinical signs for identifying autoimmune encephalitis in psychiatric patients. Front Psychiatry 8:25. https://doi.org/10.3389/fpsyt.2017.00025.eCollection 
Jack CR Jr, Bennett DA, Blennow K, Carrillo MC, Dunn B, Haeberlein SB et al (2018) NIA-AA research framework: toward a biological definition of Alzheimer's disease. Alzheimers Dement 14:535562. https://doi.org/10.1016/j.jalz.2018.02.018

Jeremy D, Schmahmann L (2019) The cerebellum and cognition. Neurosci Lett 688:62-75. https://doi.org/10.1016/j.neulet.2018.07.005

Jessen F, Spottke A, Boecker H, Brosseron F, Buerger K, Catak C et al (2018) Design and first baseline data of the DZNE multicenter observational study on predementia Alzheimer's disease (DELCODE). Alzheimers Res Ther 10:15. https://doi.org/10.1186/ s13195-017-0314-2

Langenbruch L, Bleß L, Schulte-Mecklenbeck A, Sundermann B, Brix $\mathrm{T}$, Elger CE et al (2020) Blood and cerebrospinal fluid immune cell profiles in patients with temporal lobe epilepsy of different etiologies. Epilepsia. https://doi.org/10.1111/epi.16688

Levin EC, Acharya NK, Han M, Zavareh SB, Sedeyn JC, Venkataraman V et al (2010) Brain-reactive autoantibodies are nearly ubiquitous in human sera and may be linked to pathology in the context of blood-brain barrier breakdown. Brain Res 345:221-232

Loane C, Argyropoulos GPD, Roca-Fernández A, Lage C, Sheerin F, Ahmed S, Zamboni G, Mackay C, Irani SR, Butler CR (2019) Hippocampal network abnormalities explain amnesia after VGKCC-Ab related autoimmune limbic encephalitis. J Neurol Neurosurg Psychiatry. 90:965-974. https://doi.org/10.1136/jnnp2018-320168

Malviya M, Barman S, Golombeck KS, Planagumà J, Mannara F, Strutz-Seebohm N et al (2017) NMDAR encephalitis: passive transfer from man to mouse by a recombinant antibody. Ann Clin Transl Neurol 4:768-783. https://doi.org/10.1002/acn3.444

McKeith IG, Boeve BF, Dickson DW, Halliday G, Taylor JP, Weintraub D et al (2017) Diagnosis and management of dementia with Lewy bodies: fourth consensus report of the DLB Consortium. Neurology 89:88-100. https://doi.org/10.1212/WNL.0000000000004058

McKhann GM, Knopman DS, Chertkow H, Hyman BT, Jack CR Jr, Kawas CH et al (2011) The diagnosis of dementia due to Alzheimer's disease: recommendations from the National Institute on Aging-Alzheimer's Association workgroups on diagnostic guidelines for Alzheimer's disease. Alzheimers Dement. 7:263-269. https://doi.org/10.1016/j.jalz.2011.03.005

Oporto Caroca JI, Oporto Caroca J (2019) Autoimmune retinopathy with positive anti-recoverin antibodies not associated with neoplasms: case report. Arch Soc Esp Oftalmol 94:540-544. https:// doi.org/10.1016/j.oftal.2019.07.015

Palese F, Bonomi E, Nuzzo T, Benussi A, Mellone M, Zianni E et al (2020) Anti-GluA3 antibodies in frontotemporal dementia: effects on glutamatergic neurotransmission and synaptic failure. Neurobiol Aging 86:143-155. https://doi.org/10.1016/j.neurobiola ging.2019.10.015
Papuć E, Kurys-Denis EW, Krupski W, Tatara M, Reidak K (2015) Can antiodies against glial derived antigens be early biomarkers of hippocampal demyelination and memory loss in Alzheimer's disease? J Alzheimers Dis 48:115-121. https://doi.org/10.3233/ JAD-150309

Petersen RC, Caracciolo B, Brayne C, Gauthier S, Jelic V, Fratiglioni L (2014) Mild cognitive impairment: a concept in evolution. J Intern Med 275:214-228. https://doi.org/10.1111/joim.12190

Sechi E, Flanagan EP (2019) Diagnosis and management of autoimmune dementia. Curr Treat Opt Neurol 21:11. https://doi. org/10.1007/s11940-019-0550-9

Sim KY, Im KC, Park SG (2020) The functional roles and applications of immunoglobulins in neurodegenerative disease. Int J Mol Sci 21:5295

Swayne A, Tjoa L, Broadley S, Dionisio S, Gillis D, Jacobson L et al (2018) Antiglycine receptor antibody related disease: a case series and literature review. Eur J Neurol 25:1290-1298. https://doi. org/10.1111/ene.13721

van Sonderen A, Ariño H, Petit-Pedrol M, Leypoldt F, Körtvélyessy P, Wandinger KP et al (2016) The clinical spectrum of Caspr2 antibody-associated disease. Neurology 87:521-528. https://doi. org/10.1212/WNL.0000000000002917

Wang BZ, Zailan FZ, Wong BYX, Ng KP, Kandiah N (2020) Identification of novel candidate autoantibodies in Alzheimer's disease. Eur J Neurol. https://doi.org/10.1111/ene.14290

Wattmo C, Blennow K, Hansson O (2020) Cerebro-spinal fluid biomarker levels: phosphorylated tau $(\mathrm{T})$ and total tau $(\mathrm{N})$ as markers for rate of progression in Alzheimer's disease. BMC Neurol 20:10

Wegener-Panzer A, Cleaveland R, Wendel EM, Baumann M, Bertolini $\mathrm{A}$, Häusler $\mathrm{M}$ et al (2020) Clinical and imaging features of children with autoimmune encephalitis and MOG antibodies. Neurol Neuroimmunol Neuroinflamm 7:e731. https://doi.org/10.1212/ NXI.0000000000000731

Weihua Z, Haitao R, Fang F, Xunzhe Y, Jing W, Hongzhi G (2019) Neurochondrin antibody serum positivity in three cases of autoimmune cerebellar ataxia. Cerebellum 18:1137-1142. https://doi. org/10.1007/s12311-019-01048-y (PMID: 31179511)

Wu J, Li L (2016) Autoantibodies in Alzheimer's disease: potential biomarkers, pathogenic roles, and therapeutic implications. J Biomed Res 30:361-372

Publisher's Note Springer Nature remains neutral with regard to jurisdictional claims in published maps and institutional affiliations. 